\title{
A EFICIÊNCIA DA JUSTIÇA DO TRABALHO, A PARTIR DA ANÁLISE ENVOLTÓRIA DE DADOS
}

\author{
Ana Elizabeth Neirao Reymao \\ Karla Azevedo Cebolão ${ }^{2}$ \\ 害 Alexandre Henrique Rene de Almeida Sussuarana ${ }^{3}$
}

\section{Palavras-Chave}

Eficiência/ Justiça do Trabalho/

Análise Envoltória de Dados/

Conselho Nacional de Justiça.

\section{SUMÁRIO}

\section{Introdução}

2. O Direito e a Justiça do Trabalho: breves considerações

3. Eficiência na gestão da justiça

4. Calculando a eficiência dos Tribunais Regionais do Trabalho

4.1. Sobre a Análise Envoltória de Dados (DEA)

4.2. Base de dados e definição de variáveis

\section{As eficiências calculadas}

6. Uma discussão sobre os modelos para o cálculo das eficiências dos TRTs

6.1. O uso dos portes nos cálculos dos modelos DEA de análise da eficiência da justiça brasileira: um debate preliminar

6.2. As especificações dos inputs e outputs dos modelos DEA para análise da eficiência da justiça brasileira

7. Considerações finais

8. Referências

\section{Resumo}

O artigo objetiva trazer à reflexão a eficiência dos Tribunais Regionais do Trabalho no Brasil (TRTs), discutindo sua importância na prestação da tutela judicial proposta pelas Emendas Constitucionais n 19/1998 e $n^{\circ} 45 / 2004$, bem como o modelo do Conselho Nacional de Justiça (CNJ) para o cálculo dessa eficiência. As avaliações desse Conselho envolvem o uso de indicadores, como o IPC-Jus (Índice de Produtividade Comparada da Justiça), construído a partir da Análise Envoltória de Dados (DEA). Segundo essas avaliações, a Justiça do Trabalho tem sido apontada como a mais eficiente, em comparação com as demais justiças brasileiras. Ainda assim, ela tem sido duramente criticada, chegando-se até a propor sua extinção. Sendo essa a mais eficiente das justiças brasileiras, tem-se uma contradição, ou ela não poderia assim ser avaliada? A pesquisa é aplicada, de abordagem quantitativa e qualitativa, tendo como principais fontes de informação o Justiça em Números e o banco de dados do Sistema de Estatísticas do Poder Judiciário. Apresentam-se algumas críticas às especificações adotadas no modelo DEA do CNJ e propõe-se um modelo alternativo. Os resultados mostram que, tal como nas análises do Conselho, os TRTs têm índices de eficiência elevados. Indicam, também, a necessidade de que novos dados sejam disponibilizados pelos tribunais, viabilizando estudos sobre a eficiência que considerem aspectos ligados ao atingimento dos objetivos constitucionais do judiciário. Economia (UNICAMP) professora do Programa de Pós-Graduaça
}

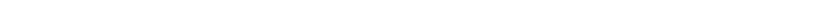




\title{
THE EFFICIENCY OF LABOR JUSTICE, BASED ON DATA ENVELOPMENT ANALYSIS
}

\author{
Ana Elizabeth Neirao Reymao \\ Karla Azevedo Cebolão \\ Alexandre Henrique Rene de Almeida Sussuarana
}

Palavras-Chave

Efficiency/ Labor justice/ Data Envelopment Analysis/ National

Council of Justice.

\section{Abstract}

The paper studies the efficiency of the Regional Labor Courts in Brazil (TRTs), discussing its importance in the provision of judicial protection proposed by Constitutional Amendments No. 19/1998 and No. 45/2004, as well as the model of the National Council of Justice (CNJ) to calculate this efficiency. The Council's assessments involve the use of indicators, such as the IPC-Jus (Comparative Productivity Index of Justice), built on Data Envelopment Analysis (DEA). According to these evaluations, Labor Court has been identified as the most efficient, in comparison with other Brazilian justices. Still, it has been harshly criticized, even going so far as to propose its extinction. Being the most efficient of the Brazilian justices, is there a contradiction, or could it not be evaluated in this way? The research is applied, of quantitative and qualitative approach, having as main sources of information the Justice in Numbers and the database of the System of Statistics of the Judiciary Power. Some criticisms are presented regarding the specifications adopted in the DEA model of CNJ and an alternative model is proposed. The results show that, as in the Council reviews, TRTs have high efficiency ratios. They also indicate the need for new data from the courts, enabling efficiency studies that consider aspects related to the attainment of the constitutional objectives of the judiciary. 


\section{Introdução}

O presente trabalho tem por objetivo trazer à reflexão a eficiência dos Tribunais Regionais do Trabalho no Brasil (TRTs), discutindo sua importância na prestação da tutela judicial proposta pelas Emendas Constitucionais $n^{\circ} 19 / 1998$ e $n^{\circ} 45 / 2004$, bem como o modelo do Conselho Nacional de Justiça (CNJ) para o cálculo dessa eficiência.

A partir de 2004, o CNJ passou a editar o Relatório Justiça em Números, avaliando os tribunais judiciários brasileiros por meio da construção de métricas. Buscando o planejamento e a gestão estratégica do Poder Judiciário, criou o IPC-Jus (Índice de Produtividade Comparada da Justiça), que efetua uma comparação da eficiência entre os tribunais do trabalho, estaduais, federais e militares, desde 2012. No texto de 2017, destacou a Justiça do Trabalho como a mais eficiente (90\%), em comparação com a Justiça Estadual (82\%) e a Justiça Federal (63\%).

O IPC-Jus é calculado a partir da Análise Envoltória de Dados (DEA - Data Envelopment Analysis). Trata-se de um método não paramétrico de programação linear que visa avaliar a capacidade de uma unidade de produção (DMU - Decision Making Unit) transformar seus recursos em produtos. Ao aplicá-lo, os tribunais judiciários são compreendidos como unidades de produção para as quais se define um modelo de entradas e saídas que transformam recursos (inputs) em produtos (outputs).

O objetivo da DEA é identificar os tribunais eficientes e os não eficientes, comparando o conjunto de inputs e outputs de cada um. A partir dela pode-se mensurar a capacidade de cada um transformar insumos em produtos, explica Fochezatto (2010).

Esse tema, que envolve a administração da justiça, é um tema pouco explorado nos estudos brasileiros, notadamente quando a abordagem é acerca da mensuração da eficiência do Poder Judiciário. Ainda que, como princípio, a eficiência tenha sido elevada à condição de constitucional, muito ainda há que se aperfeiçoar nos mecanismos gerenciais em favor do atendimento dos direitos dos cidadãos, produzindo indicadores que espelhem esse objetivo.

Nesse contexto, o presente artigo versa sobre a eficiência dos TRTs, destacando a importância do direito e da Justiça do Trabalho, os quais têm sido duramente criticados, chegando-se até a propor sua extinção, como será aqui mostrado. Sendo essa a mais eficiente das justiças brasileiras, tem-se, então, uma contradição, ou não seria essa justiça eficiente?

Para investigar esse problema de pesquisa, o artigo usou a metodologia de pesquisa aplicada, de abordagem quantitativa, empregando o método DEA para identificar os TRTs eficientes e ajudar a aperfeiçoar a eficiência dos demais. Empregou também a abordagem qualitativa para discutir o modelo de cálculo das eficiências dos TRTs apresentado pelo CNJ. Quanto aos procedimentos, a pesquisa foi bibliográfica e documental, tendo como principais fontes de informação o banco de dados do Sistema de Estatísticas do Poder Judiciário, disponível no sítio oficial do CNJ na internet e de acesso público, conforme dispõe a Portaria $n^{\circ}$ 216, de 19 de dezembro de 2012, bem como os Relatórios Justiça em Números.

O texto está estruturado em sete seções, incluindo essa introdução e as considerações finais. Na seção dois são apresentadas 
breves considerações acerca do Direito e da Justiça do Trabalho. A seção três discute a eficiência na gestão da justiça. A seção seguinte apresenta os aspectos metodológicos da presente pesquisa: o método DEA, as fontes de informações e a definição de variáveis do modelo proposto para o cálculo das eficiências dos TRTs. Na seção cinco tem-se os resultados dos referidos cálculos, cuja discussão é efetuada na seção seguinte.

\section{Direito e a Justiça do Trabalho: breves considerações}

A precarização e a exploração do trabalho humano decorrente da Revolução Industrial levaram ao surgimento do direito do trabaIho (Cassar, 2017). A utilização da máquina a vapor, que viabilizou a produção em grande escala, bem como a introdução de outras inovações trazidas por essa revolução, que retiraram postos de trabalho dos empregados e dificultaram a barganha entre esses e os empregadores, fizeram emergir conflitos e pressionaram para a regulação das relações de trabalho.

Porém, a ideologia liberal, adotada à época, defendia a ideia de intervenção mínima do Estado na economia e nas relações de trabalho. Segundo seus ditames, era livre a contratação das condições de trabalho, o que, para os empregados, representava situações como a exploração de mulheres e crianças, inclusive em situações insalubres e perigosas, a grande incidência de acidentes de trabalho, jornadas sem descanso, com duração excessiva e salários muito baixos, entre outras adversidades, lembradas por Alexandrino et al. (2006).

Devido a essas péssimas condições, os trabalhadores pressionavam por uma maior intervenção estatal nessas relações, uma vez que a liberdade para contratar estava trazendo consequências muito negativas para estes. Começaram a surgir conflitos com as associações de empregados e em outras organizações, em busca de melhorias gerais de trabalho.

$\mathrm{Na}$ Inglaterra, em 1802, surgiram as primeiras leis trabalhistas. No Brasil, essa política iniciou-se em 1930, com Getúlio Vargas e, em $1^{\circ}$ de maio de 1943, a Consolidação das Leis do Trabalho (CLT) foi aprovada pelo Decreto-Lei n 5.452. Naquela época, a ideologia política do governo foi o trabalhismo, assim como o corporativismo para a estrutura sindical. Esse contexto leva alguns autores, como Delgado (2013), a destacarem que a CLT foi planejada e editada em um momento de profunda centralização e autoritarismo políticos.

Como explica o autor, o processo histórico legislativo trabalhista brasileiro passou por três fases: de 1930 a 1945: período de institucionalização do Direito do Trabalho; de 1945 a 1988: período de expansão da legislação trabalhista, a partir de 1988 até os dias atuais: período de consolidação democrática constitucional do direito do trabalho brasileiro (Delgado, 2013). Nessa última fase, chamada de constitucionalismo social por Martins (2017), as constituições dos países passaram a tratar dos direitos trabalhistas, sociais e econômicos.

Começava a haver uma significativa mudança de comportamento, com a substituição do cidadão/indivíduo da doutrina liberal pelo cidadão/trabalhador, em que o trabalho passou a ser visto como algo que valorizava o homem, tornando-o digno de respeito e da proteção da sociedade, pois era uma forma de emancipação da personalidade.

Nessa linha, a construção e progresso das 
atividades laborais regulado no país teve na CLT um papel decisivo, principalmente, levando-se em consideração a realidade normativa brasileira precária, existente até a década de 1930. A CLT também trouxe a institucionalização de um modelo de contratação trabalhista próprio, deixando de lado o individualismo e o formalismo das relações civilistas clássicas, apresentando maior isonomia material.

Apesar da importância do direito do trabalho, mostrando-se necessário para a observância das garantias mínimas para os trabalhadores, bem como para a criação de um ambiente laboral mais favorável, Gomes (2006) lembra que esse ainda era visto como direito menor, portador de uma cultura de desprestígio, por ser volta voltada para problemas sociais, com busca de soluções conciliatórias e maior informalidade no julgamento dos processos. Nessa linha, eram consideradas características negativas a oralidade, gratuidade e acessibilidade da Justiça do Trabalho.

Entretanto, são justamente essas características que fazem da mesma minimizadora de desigualdades, uma vez que, juridicamente, estabelece maior equilíbrio entre empregador e empregado, economicamente mais fraco. Voltada para o atendimento do cidadão comum, e com dimensão intervencionista e protecionista do Estado em relação ao trabalhador, permite a necessária estabilidade das relações sociais. Além de combater a prevalência dos princípios econômicos sobre o ser humano, uma vez que é um direito em conflito permanente com a economia (Gomes, 2006).

Com o advento da Constituição Federal de 1988 (CF/88), que estabelece o direito fundamental ao trabalho, dando centralidade à pessoa humana, a Justiça do Trabalho passou a ser vista como uma justiça moderna, contando com procedimentos necessários para ter maior eficiência.

Apesar disso, a possibilidade de sua extinção tem sido discutida, ganhando força esse debate no final do século XX. Por exemplo, o governo Fernando Henrique Cardoso foi um duro crítico do modelo tradicional de relações trabalhistas e um dos que propôs a extinção da Justiça do Trabalho:

\begin{abstract}
Preconizando o "fim da era Vargas", o governo Fernando Henrique Cardoso (1994-2002) investiu duramente contra o modelo tradicional de relações trabaIhistas, chegando mesmo a propor a extinção da Justiça do Trabalho. Várias inovações legislativas foram sendo tentadas e, embora algumas terminassem de fato por flexibilizar formas de contratação e propiciar novos espaços de negociação trabalhista a Justiça do Trabalho escapou ilesa, graças à firme reação das associações profissionais do setor jurídico e de sindicatos dos trabalhadores (Morel \& Pessanha, 2007, p. 92).
\end{abstract}

Mais recentemente, em momento de crise econômica e com o aumento do número de desempregados no país, por ocasião do debate sobre a Reforma Trabalhista (Lei n. 13.467/2017), novamente o tema da extinção foi enfatizado.

Em uma entrevista, o presidente nacional do Partido Trabalhista Brasileiro (PTB) defendeu o fim da Justiça do Trabalho, destacando seu alto custo em meio a afirmações, no mínimo, deselegantes:

É socialista e populista. Não consigo entender o custo benefício dela. Temos $2 \%$ da mão de obra regular, reconhecida como carteira assinada, e 85\% das reclamações trabalhistas do mundo. O que mostra que é uma indústria do reclamante, porque o reclamado sempre perde. A Justiça do Trabalho custou ano passado R\$ 22 bilhões para dar de soluções entre indenizações e acordos menos de $R \$ 8$ 
bilhões. Ela é a babá mais cara do mundo. Você não tem defesa na Justiça do Trabalho. Nós tínhamos que acabar com a Justiça do Trabalho, porque ela é uma excrescência brasileira, e julgar na Justiça comum (Uribe \& Carvalho, 2018, p. 1).

Tal afirmação gerou uma nota pública do presidente do Tribunal Superior do TrabaIho (TST), ministro Ives Gandra Filho, na qual defendeu que os argumentos apresentados pelo político não condizem com os fatos, uma vez que ela é a que mais julga, mais eficiente e a que mais concilia. Afirmou, ainda, que não é função da Justiça do Trabalho arrecadar fundos para os cofres públicos, sendo seu papel o de pacificar os conflitos nas relações de trabalho (Uribe \& Alegretti, 2018, p. 1).

Como se observa, argumenta-se ser essa justiça custosa, prejudicial ao crescimento econômico. O que não se diz é que a questão do elevado custo é uma crítica dirigida a todo o Poder Judiciário, ${ }^{4}$ não sendo matéria exclusiva da Justiça do Trabalho.

Por sua vez, a ideia de que o crescimento econômico é prejudicado pelo mau funcionamento do judiciário, que reduz a competitividade do país (Castelar Pinheiro, 2009), está longe de constituir consenso. Discordando de posições voltadas para a economia de mercado, Leal (2010) defende a ideia de que atos, fatos e negócios jurídicos sempre devem ser dirigidos pelos direitos e garantias da república, definindo as relações de mercado.

Dessa maneira, as normas constitucionais é que devem orientar a relação entre economia e direito. A CF/88 apartou o desenvolvimento social do crescimento econômico, quando nela introduziu os valores sociais do trabalho e a livre-iniciativa como funda-

\footnotetext{
Da Ros (2015) argumenta que a despesa do Poder Judiciário brasileiro é onerosa, ficando em torno de 1,4\% do Produto Interno Bruto, enquanto na Espanha é de $0,12 \%$; na Inglaterra, $0,14 \%$; nos Estados Unidos, 0,14\%; e no Chile, 0,22\%.
}

mento da República Federativa do Brasil (art. $1^{\circ}$ ) e princípio geral da atividade econômica (art. 170).

Portanto, a justificativa em favor da extinção da Justiça do Trabalho não é bem qualificada e, em nosso entender, não procede. Certamente há muitas questões a serem discutidas quanto ao funcionamento da justiça brasileira, mas essas não podem estar assentadas em meros juízos de valor sem vínculos com uma avaliação fundamentada de seu funcionamento.

Essa avaliação precisa ser pautada em critérios que estejam de acordo com as aspirações sociais, definidos constitucionalmente e capazes de dar efetividade ao papel que deve por ela ser desempenhado. Dentre os vários critérios possíveis e expressos na CF/88, emerge a questão da eficiência, como os movimentos de reforma do judiciário têm reivindicado.

Uma vez que o ordenamento jurídico brasileiro prevê a eficiência como norma-princípio da administração pública (art. 37, caput, da Constituição da República) e a atividade judiciária é considerada um serviço público essencial, parece muito mais adequado discuti-la como critério de avaliação de seu funcionamento e formular possíveis críticas, como faz o presente artigo.

\section{Eficiência na gestão da justiça}

A importância de uma política jurisdicional de qualidade tem sido cada vez mais defendida pela sociedade. A nova realidade social tem pressionado o Estado a se adequar, transformado a administração pública contemporânea e redesenhado a utilização dos 
recursos públicos escassos (Calhao, 2007). Nesse contexto, a busca por uma gestão pública voltada para o resultado assumiu relevância para o oferecimento de serviços públicos de qualidade à população. Enquanto administração pública, o Poder Judiciário também foi pressionado a se enquadrar aos novos ditames, promovendo uma tutela jurisdicional eficiente.

Em termos constitucionais, a importância da eficiência começou a ser desenhada com a Emenda Constitucional n 19/1998, chamada de reforma da Administração Pública, que nela introduziu o princípio da eficiência. Segundo ele, a Administração Pública deve trazer resultados positivos para - serviço público, havendo o satisfatório atendimento das necessidades da sociedade e não, simplesmente, desempenhar seu papel com legalidade, destacam Camargo e Guimarães (2013).

Zaidan (2012, p. 25) assim conceitua eficiência:

Trata-se de uma relação entre o resultado e os meios utilizados para tal, deve ser um ato de racionalidade entre os custos necessários e o grau de utilidade almejado, que tenha como finalidade atingir boa prestação de serviços de maneira rápida, simples e econômica, considerando o custo/benefício da atividade.

Nessa linha, a EC n 19/98 teve como finalidade alcançar maior flexibilidade no dinamismo do Estado e no aparato normativo, adquirindo, portanto, maior eficiência e celeridade na máquina administrativa estatal e proporcionando melhor qualidade na prestação do serviço público (Gonçalves \& Souza, 2014).

O agir do Estado deve ser otimizado, devendo-se aumentar a qualidade dos serviços, em que os agentes públicos devem agir com rapidez, presteza, perfeição e rendimento (Camargo \& Guimarães, 2013). Nes- ses termos, o princípio da eficiência foi positivado para dar uma satisfação à população que clamava por uma administração rápida, porém com qualidade na entrega de sua atividade fim (Marco \& Medeiros, 2016).

Em 2004, a edição da Emenda Constitucional $n^{\circ} 45$, chamada reforma do Poder Judiciário, se deveu, justamente, pela necessidade de uma justiça mais ágil e eficiente, em que a moralidade, transparência e coordenação administrativa fossem o objetivo. A consolidação do Estado Democrático de direito e o fortalecimento do Poder Judiciário sob o apoio da CF/88 era o objetivo a ser alcançado, pois só um sistema legal sólido e eficaz pode assegurar a solução rápida dos litígios e a segurança jurídica (Peluso, 2010).

Uma das inovações da Emenda foi a criação do CNJ, órgão responsável pelo controle administrativo e financeiro do judiciário brasileiro e uma das plataformas de democratização desse Poder, tendo suas competências estabelecidas no $\S 4^{\circ}$ do art. 103-B da CF/88 (Calhao, 2010).

No cumprimento dessa função, organiza dados estatísticos com o fim de dar mais transparência à atuação do judiciário brasileiro (Zaidan, 2012, p. 34). Tais medidas foram uma resposta à chamada crise do judiciário, ${ }^{5}$ cuja estrutura seria pesada e sem agilidade, deixando insatisfeita a sociedade por ser "incapaz de fornecer soluções em tempo razoável, previsíveis e a custos acessíveis a todos" (Sadek, 2004, p. 88).

Tribunais sobrecarregados, um elevado número de processos em trâmite que, em

${ }^{5}$ Uma discussão dessa crise foge aos objetivos do presente texto. Suas possíveis causas são discutidas por autores como Sadek (2004), Gico Júnior (2014), Moreira (2004), Leal (2010) e Faria (2005). Fatores como a complexidade do sistema jurídico legal no Brasil, a burocracia, a insuficiência de recursos materiais e humanos, a formalidade nos procedimentos, a falta de gestão, além da incompatibilidade da arquitetura do judiciário com a elevada desigualdade da sociedade brasileira estão entre os motivos apontados por eles. 
2009, passava de 83,4 milhões, chegando a 92,2 milhões em 2012, ao lado do crescimento acelerado do número de casos novos (8,4\% em 2012), segundo dados do Justiça em Números (CNJ, 2013), evidenciavam o que Faria (2005) chamou de encruzilhada: a negação de justiça à população de baixa renda, ao lado da acusação de disseminação de insegurança no mundo dos negócios e de multiplicação de custos indiretos aos que argumentavam que a ausência de proteção legal compromete o crescimento econômico.

Ou seja, o CNJ, criado sob o discurso de assegurar o interesse social por maior transparência do Poder Judiciário, passou a realizar o controle externo da magistratura, impulsionar sua otimização e buscar a excelência do seu desempenho.

A partir de 2006, passou a desenvolver sistemas de mensuração, recolhendo e sistematizando dados estatísticos no que concerne a aspectos diretamente relacionados às organizações judiciárias brasileiras, como insumos, dotações orçamentárias e dados sobre litigiosidade e acesso à justiça, divulgando os resultados por meio de relatório anual Justiça em Números.

Nessa mesma época, começou a ser usado um método de construção de fronteiras de produção, a chamada Data Envelopment Analysis (DEA) ou Análise Envoltória de Dados, que utiliza indicadores de eficiência no campo da medição do desempenho produtivo e organizacional. Trata-se de um método voltado à análise técnica de unidades produtivas não tradicionais que utilizam múltiplos insumos para a produção de múltiplos bens ou serviços, tema detalhado na próxima sessão.

\section{Calculando a eficiência dos Tribunais Regionais do Trabalho}

Essa seção apresenta os aspectos metodológicos da presente pesquisa, destacando o método DEA, bem como as fontes de informações e a definição de variáveis do modelo adotado para o cálculo das eficiências dos TRTs.

\subsection{Sobre a Análise Envoltória de Dados (DEA)}

A avaliação dos tribunais judiciários por meio do método DEA implica em estabelecer uma fronteira de eficiência, a qual é composta pelos tribunais de máxima produtividade no processo de transformação de insumos em produtos.

Empregando-se a terminologia desse método não paramétrico de programação linear, o que se pretende é avaliar a capacidade da unidade de produção (DMU, do inglês Decision Making Unit) em transformar os recursos em produtos. Os tribunais judiciários, enquanto unidades de produção, podem ser representados por um modelo de entradas e saídas que transformam recursos (inputs) em produtos (outputs).

O objetivo da análise é identificar os tribunais eficientes e os não eficientes, comparando o conjunto de inputs e outputs de cada um. Assim, o DEA mensura a capacidade de cada DMU, que realiza tarefas similares, transformar insumos em produtos (Fochezatto, 2010).

Considera-se eficiência a relação entre os produtos resultantes de um processo produtivo e a quantidade de recursos utilizados pela DMU, obtendo-se uma medida numérica, dada por:

$E=($ Output/Input), sendo $E$ a eficiência. 
Como se observa, trata-se de um critério que revela a capacidade de a organização de produzir um máximo de resultados com um mínimo de recursos.

Identificadas as unidades mais eficientes, essas passam a servir como benchmark para as demais, ou seja, como referencial para comparação com as outras. Trata-se, pois, de uma análise de eficiência relativa ${ }^{6}$ : todas as DMUs estão sendo comparadas às unidades eficientes, ou seja, às que estão na fronteira. A análise envoltória baseia-se no estabelecimento da fronteira ${ }^{7}$ formada pelas DMUs mais eficientes, sendo a distância de cada DMU até essa fronteira o grau de ineficiência, como explicam Yeung e Azevedo (2012).

O grau de eficiência calculado pelo método DEA é uma medida que varia de zero a um (0 a 100\%), em que um representa eficiência relativa de 100\%. Quando menor que um, tem-se que a DMU é ineficiente em X\%. Exemplificando: se o tribunal "A" tem uma eficiência de 0,7 ou 70\%, quer dizer que é ineficiente em 0,3 ou 30\% e, para ser eficiente, precisa melhorar 30\%.

Vale ressaltar que, ao se tratar de eficiência relativa, quando um tribunal apresentar 100\% de eficiência isso não significa que ele não pode melhorar. Representa apenas que, Embora o conceito de eficiência já traga a ideia de comparação a um padrão e, por isso, o uso da expressão "eficiência relativa" pareça redundante, os estudos que empregam a Análise Envoltória de Dados (DEA) convencionam usá-la, como se vê em Fochezatto (2010), Yeung e Azevedo (2009, 2012), Nogueira et al. (2012), Souza (2015) e Zaidan (2011). Isso decorre do fato de que é necessário deixar claro que a eficiência calculada é "relativa", pois mesmo que uma DMU seja 100\% eficiente, ainda assim ela poderá melhorar seus resultados e se aproximar cada vez mais da "eficiência absoluta". O cálculo dessa "eficiência absoluta" implicaria o conhecimento do resultado máximo que a DMU pode alcançar com seus recursos. Ocorre que esse é um valor teórico e inatingível (ideal), que o pesquisador não conhece. Então, diz-se que as eficiências calculadas pelo método DEA são "eficiências relativas" porque é baseado nos resultados das DMU mais eficientes em análise. Assim, o presente artigo optou por seguir a literatura e usar a expressão "eficiência relativa".

As unidades eficientes são unidas formando uma superfície côncava, hiperplanos, sendo as DMUs ineficientes projetadas ortogonalmente na fronteira. Para o cálculo do índice de eficiência, projeta-se as unidades ineficientes nessa fronteira e a distância da unidade até a mesma fornece o grau de ineficiência. em relação aos demais, é o que tem melhor resultado output/input.

Na aplicação do método DEA e cálculo da eficiência, faz-se necessário observar alguns passos, dentre os quais destacam-se: selecionar as DMUs, descrever o processo produtivo para identificar os inputs e outputs, escolher entre retornos constantes ou variáveis de escala, bem como o tipo de orientação (se para o output ou para input ou, ainda, sem orientação). ${ }^{8}$

Nesse artigo, optou-se por um modelo com retornos constantes de escala, o "Modelo CCR", originalmente desenvolvido por Charnes, Cooper e Rhodes (1978), no qual se assume que o aumento dos recursos utilizados gera retornos proporcionais, constantes no produto gerado.

Essa hipótese de retornos constantes de escala é adotada tanto pelo $\mathrm{CNJ}$, como pela literatura aplicada ao judiciário brasileiro, a exemplo de Fochezatto (2010), Yeung e Azevedo (2009, 2012), Nogueira et al. (2012), Souza (2015) e Zaidan (2011). ${ }^{9}$ O argumento é de que há uma tendência de os magistrados analisarem caso a caso o que, em combinação com a alta burocracia, com o excessivo detalhamento de procedimentos a serem cumpridos por um processo no tribunal, além da não tradição de os mesmos seguirem precedentes (mesmo sob a vigência do Novo Código de Processo Civil), resulta em uma certa proporcionalidade entre os recursos e os produtos dos tribunais.

O modelo CCR (das iniciais de Charnes, Coo-

\footnotetext{
Os principais modelos DEA são os orientados (modelos CCR (Charnes, Cooper e Rhodes) e o BCC (Banker, Charnes e Cooper)), o aditivo (também denominado não orientado) e o FDH (Free Disposal Hull).

${ }^{9} \mathrm{O}$ método DEA também pode ser empregado sob a hipótese de retornos variáveis de escala, mas poucos são os trabalhos o fazem. Dentre eles, cita-se Santos Neto et al. (2016), ao estudarem a eficiência dos Tribunais Estaduais brasileiros, e Kittelsen e Forsund (1992). Esses últimos, ao analisarem as cortes distritais da Noruega, supuseram as hipóteses de retornos constantes de escala e retornos variáveis.
} 
per e Rhodes) compara $n$ unidades (DMUs) com s outputs denotados de $; r=1 \ldots \mathrm{s}$; e $\mathrm{m}$ inputs denotados por , $\mathrm{i}=1 \mathrm{fm}$, em que a eficiência da DMU $k$ dada por:

$$
h_{k}=\operatorname{Max}_{u r, v i} \frac{\sum_{r=1}^{s} u_{r} y_{r k}}{\sum_{i=1}^{m} v_{i} x_{i k}} \text {, }
$$

sendo os pesos $u_{r}$ e $v_{i}$ não negativos: $u_{r}, v_{i} \geq 0$

Um segundo conjunto de restrições requerido é que nenhuma DMU tenha eficiência maior que um:

$$
\frac{\sum_{r=1}^{S} u_{r} y_{r j}}{\sum_{i=1}^{m} v_{i} x_{i j}} \leq 1 \text { para } \mathrm{j}=1, \ldots, \mathrm{n}
$$

Outra característica do modelo empregado nesse artigo é a orientação para o output, ou seja, os resultados da análise dirão se o TRT produz o máximo possível (100\%) com os insumos disponíveis e indicarão o quanto - Tribunal poderia aumentar seus outputs, mantendo-se o nível de inputs inalterados.

Caso a opção fosse de orientação para o input, - método DEA avaliaria o uso dos recursos (inputs) para um dado produto (output) e questionamento seria diferente: "O TRT usa os insumos de modo eficiente?". Porém, advertem Yeung e Azevedo (2012), a escolha da orientação do modelo depende de sobre quais fatores (inputs ou outputs) os gestores têm como influir no processo produtivo estudado.

Em geral, os insumos (inputs) do Judiciário são definidos pelo Poder Legislativo, Poder Executivo ou mesmo pela hierarquia superior dos órgãos judiciais. Portanto, os tribunais não determinam esses insumos, o que justifica a orientação para o output do modelo. ${ }^{10}$

'Fochezatto (2010) e Santos Neto et al. (2016) adotaram orientação para o input em seus trabalhos.
Definidas essas características, passou-se à definição dos outputs e inputs a serem usados, o que se discute a seguir.

\subsection{Base de dados e definição de variáveis}

O estudo utilizou informações sobre os TRTs em 2016, extraídas do banco de dados do Sistema de Estatísticas do Poder Judiciário que, como já referido, são de acesso público no sítio oficial do CNJ na internet.

Portanto, os dados foram obtidos da mesma base utilizada na elaboração do Justiça em Números, relatório anualmente publicado pelo Conselho. Criado em agosto de 2005, esse Sistema teve por objetivo concentrar e analisar os dados encaminhados por todos os Tribunais do país para, a partir deles, produzir indicadores de diagnóstico sobre o Poder Judiciário e orientar seu planejamento estratégico (CNJ, 2008).

Os inputs e outputs escolhidos foram:

- Inputs:

a) Pessoal auxiliar efetivo

b) Magistrados do primeiro grau

c) Magistrados do segundo grau

d) Tempo médio das sentenças de $1^{\circ}$ e $2^{\circ}$ Graus

Outputs:

a) Sentenças de primeiro grau

b) Decisões de segundo grau

Como se observa, foram selecionados como inputs os recursos de pessoal dos Tribunais Regionais do Trabalho, bem como o tempo em que desenvolvem suas atividades. 
O modelo proposto, portanto, aproxima-se do apresentado por Yeung e Azevedo (2012), mas inova por incluir a variável "tempo médio das sentenças" como input, uma vez que a morosidade na prestação jurisdicional é a principal dimensão que afeta a confiança no Judiciário.

Os dados sobre o tempo dos processos não estavam disponíveis à época do estudo de Yeung e Azevedo (2012) e ainda hoje é uma informação incompleta nos Relatórios. Os primeiros dados desagregados foram disponibilizados somente a partir de 2015.

Os valores usados no modelo foram os disponíveis no Relatório Justiça em Números 2017, listados na Tabela 1, ao final dessa seção.

Como output, optou-se por sentenças e decisões de segundo grau, entendendo-se que aqueles produtos mais se aproximam de procedimentos relativos à prestação dos serviços públicos à sociedade, bem como estão meIhor adequados aos inputs escolhidos.

Selecionadas essas variáveis, bem como optando-se por retornos constantes de escala e orientação para o output, o método foi aplicado utilizando-se o software livre R, disponível em https://www.r-project.org/ e seu pacote rDEA para calcular as eficiências.

As eficiências foram calculadas de duas maneiras distintas: uma considerando a classificação por portes adotada pelo CNJ (2017), que divide os tribunais em três grupos: grande, médio e pequeno porte; e outra sem essa classificação, resultando em dois índices:

(1) Índice de Eficiência por Porte (IEP): mostra o nível de eficiência relativa do Tribunal quando comparado com os demais do mesmo porte, em mesmo ano. Os portes considerados foram os mesmos definidos pela metodologia do CNJ que, por meio da análise multivariada denominada análise de componentes principais, considera quatro variáveis para o cálculo desses portes: despesa total da justiça, total de processos que tramitaram, total de magistrados e força de trabalho (CNJ, 2007).

(2) Índice de Eficiência Geral (IEG): expressa o grau de eficiência relativa do TRT em comparação com os demais, em um ano específico.

Os dados utilizados estão abaixo listados e os resultados são discutidos na seção a seguir.

Tabela 1 - Base de dados brutos (2016)

\begin{tabular}{|l|l|r|r|r|r|l|r|r|r|}
\hline \multicolumn{1}{|c|}{ SIGLA } & \multicolumn{1}{|c|}{ TPS } & TPEFET & MAG1 & MAG2 & \multicolumn{1}{c|}{ PORTE } & TMSD & DEC2 & SENTC1 \\
\hline TRT1 & Rio de Janeiro & 7 & 4029 & 270 & 54 & Grande & 19 & 73847 & 264485 \\
\hline TRT2 & São Paulo & 422 & 5453 & 383 & 93 & Grande & 12 & 136590 & 459932 \\
\hline TRT3 & Minas Gerais & 2 & 3679 & 233 & 48 & Grande & 16 & 105629 & 272271 \\
\hline TRT4 & Rio Grande do Sul & 12 & 3411 & 227 & 47 & Grande & 20 & 88269 & 184026 \\
\hline TRT5 & Bahia & 126 & 2135 & 164 & 29 & Médio & 25 & 38657 & 116935 \\
\hline TRT6 & Pernambuco & 136 & 1611 & 126 & 19 & Médio & 12 & 28057 & 117822 \\
\hline TRT7 & Ceará & 48 & 950 & 63 & 14 & Médio & 17 & 11925 & 66588 \\
\hline TRT8 & Pará e Amapá & 4 & 1316 & 85 & 22 & Médio & 9 & 16690 & 95386 \\
\hline TRT9 & Paraná & 150 & 2403 & 176 & 30 & Médio & 17 & 56253 & 150681 \\
\hline TRT10 & Distrito Federal e Tocantins & 26 & 1029 & 79 & 17 & Médio & 15 & 20053 & 62568 \\
\hline TRT11 & Amazonas e Roraima & 39 & 928 & 47 & 13 & Médio & 13 & 11497 & 63438 \\
\hline TRT12 & Santa Catarina & 7 & 1631 & 97 & 17 & Médio & 11 & 32703 & 93713 \\
\hline TRT13 & Paraíba & 50 & 975 & 53 & 10 & Médio & 12 & 7979 & 39727 \\
\hline
\end{tabular}




\begin{tabular}{|l|l|r|r|r|r|l|r|r|r|}
\hline TRT14 & Rondônia e Acre & 28 & 774 & 47 & 8 & Pequeno & 8 & 11690 & 27938 \\
\hline TRT15 & São Paulo (Campinas) & 15 & 3306 & 326 & 55 & Grande & 24 & 112626 & 311076 \\
\hline TRT16 & Maranhão & 5 & 489 & 42 & 8 & Pequeno & 16 & 7268 & 34394 \\
\hline TRT17 & Espírito Santo & 42 & 665 & 51 & 12 & Pequeno & 16 & 19100 & 39209 \\
\hline TRT18 & Goiás & 2 & 1325 & 86 & 13 & Médio & 10 & 25404 & 95724 \\
\hline TRT19 & Alagoas & 56 & 558 & 40 & 8 & Pequeno & 18 & 6506 & 34696 \\
\hline TRT20 & Sergipe & 2 & 435 & 27 & 8 & Pequeno & 12 & 8359 & 25897 \\
\hline TRT21 & Rio Grande do Norte & 61 & 677 & 41 & 10 & Pequeno & 7 & 9921 & 34014 \\
\hline TRT22 & Piauí & 14 & 327 & 26 & 8 & Pequeno & 12 & 9142 & 28397 \\
\hline TRT23 & Mato Grosso & 3 & 786 & 66 & 8 & Pequeno & 11 & 11972 & 41843 \\
\hline TRT24 & Mato Grosso do Sul & 2 & 558 & 49 & 8 & Pequeno & 14 & 12031 & 32392 \\
\hline
\end{tabular}

Fonte: Banco de dados do Sistema de Estatísticas do Poder Judiciário (CNJ, 2017)

Notas:

TPS = Total de Pessoal que saiu por cessão ou requisição

TPEFET $=$ Total de pessoal do quadro efetivo

MAG1 = Total de Magistrados no $1^{\circ} \mathrm{Grau}$

MAG2 = Número de Magistrados no $2^{\circ}$ Grau

TMSD = Tempo médio das sentenças e decisões

DEC2 = Decisões do $2^{\circ} \mathrm{Grau}$

SENTCl $=$ Sentenças do $1^{\circ}$ Grau

Pessoal Auxiliar Efetivo $=$ TPS + TPEFET

\section{As eficiências calculadas}

Os resultados da avaliação de eficiência dos TRTs podem ser observados na Tabela 2. Nela são mostradas as eficiências calculadas conforme modelo DEA proposto nesse trabalho (colunas A e B), o IPC-Jus, calculado pelo CNJ para medir a eficiência dos tribunais judiciários brasileiros (coluna $C$ ), bem como algumas comparações, conforme detalhado a seguir.

Os dados mostram uma elevada eficiência da Justiça do Trabalho, com 6 tribunais na fronteira de eficiência (100\%), segundo o IEG (coluna A): TRT 2 (São Paulo), TRT 3 (Minas Gerais), TRT 11 (Amazonas e Roraima), TRT 15 (Campinas, SP), TRT 18 (Goiás) e TRT 22 (Piauí).

Tabela 2 - Medidas de eficiência dos tribunais do trabalho brasileiros (2016)

\begin{tabular}{|l|l|l|l|l|l|l|c|}
\hline \multicolumn{1}{|c|}{ Sigla } & \multicolumn{1}{|c|}{ UF } & Porte & $\begin{array}{c}\text { IEG } \\
\text { (A) }\end{array}$ & & $\begin{array}{c}\text { IEP } \\
\text { (B) }\end{array}$ & IPC-Jus & IEG - \\
(C) & & IEG - IEP (A-B)* & $\begin{array}{c}\text { IPC-Jus } \\
\text { (A-C)* }\end{array}$ \\
\hline TRT1 & Rio de Janeiro & Grande & $86 \%$ & $86 \%$ & $81 \%$ & $-1 \%$ & $5 \%$ \\
\hline TRT2 & São Paulo & Grande & $100 \%$ & $100 \%$ & $93 \%$ & $0 \%$ & $7 \%$ \\
\hline TRT3 & Minas Gerais & Grande & $100 \%$ & $100 \%$ & $100 \%$ & $0 \%$ & $0 \%$ \\
\hline TRT4 & Rio Grande do Sul & Grande & $88 \%$ & $88 \%$ & $82 \%$ & $0 \%$ & $6 \%$ \\
\hline TRT5 & Bahia & Médio & $66 \%$ & $81 \%$ & $81 \%$ & $-15 \%$ & $-15 \%$ \\
\hline TRT7 & Pernambuco & Médio & $86 \%$ & $96 \%$ & $91 \%$ & $-9 \%$ & $-5 \%$ \\
\hline TRT8 & Ceará & Médio & $89 \%$ & $93 \%$ & $90 \%$ & $-4 \%$ & $-1 \%$ \\
\hline
\end{tabular}




\begin{tabular}{|c|c|c|c|c|c|c|c|}
\hline TRT9 & Paraná & Médio & $86 \%$ & $100 \%$ & $86 \%$ & $-14 \%$ & $0 \%$ \\
\hline TRT1O & $\begin{array}{l}\text { Distrito Federal e } \\
\text { Tocantins }\end{array}$ & Médio & $72 \%$ & $92 \%$ & $80 \%$ & $-20 \%$ & $-8 \%$ \\
\hline TRT11 & $\begin{array}{l}\text { Amazonas e Ro- } \\
\text { raima }\end{array}$ & Médio & $100 \%$ & $100 \%$ & $100 \%$ & $0 \%$ & $0 \%$ \\
\hline TRT12 & Santa Catarina & Médio & $90 \%$ & $100 \%$ & $94 \%$ & $-10 \%$ & $-4 \%$ \\
\hline TRT13 & Paraíba & Médio & $63 \%$ & $63 \%$ & $82 \%$ & $0 \%$ & $-19 \%$ \\
\hline TRT14 & Rondônia e Acre & Pequeno & $66 \%$ & $100 \%$ & $92 \%$ & $-34 \%$ & $-26 \%$ \\
\hline TRT15 & $\begin{array}{l}\text { São Paulo (Cam- } \\
\text { pinas) }\end{array}$ & Grande & $100 \%$ & $100 \%$ & $100 \%$ & $0 \%$ & $0 \%$ \\
\hline TRT16 & Maranhão & Pequeno & $80 \%$ & $100 \%$ & $70 \%$ & $-20 \%$ & $10 \%$ \\
\hline TRT17 & Espírito Santo & Pequeno & $90 \%$ & $100 \%$ & $92 \%$ & $-10 \%$ & $-2 \%$ \\
\hline TRT18 & Goiás & Médio & $100 \%$ & $100 \%$ & $99 \%$ & $0 \%$ & $1 \%$ \\
\hline TRT19 & Alagoas & Pequeno & $75 \%$ & $100 \%$ & $83 \%$ & $-25 \%$ & $-8 \%$ \\
\hline TRT20 & Sergipe & Pequeno & $80 \%$ & $90 \%$ & $79 \%$ & $-11 \%$ & $1 \%$ \\
\hline TRT21 & $\begin{array}{l}\text { Rio Grande do } \\
\text { Norte }\end{array}$ & Pequeno & $67 \%$ & $100 \%$ & $90 \%$ & $-33 \%$ & $-23 \%$ \\
\hline TRT22 & Piauí & Pequeno & $100 \%$ & $100 \%$ & $96 \%$ & $0 \%$ & $4 \%$ \\
\hline TRT23 & Mato Grosso & Pequeno & $75 \%$ & $100 \%$ & $83 \%$ & $-25 \%$ & $-8 \%$ \\
\hline TRT24 & Mato Grosso do Sul & Pequeno & $71 \%$ & $100 \%$ & $74 \%$ & $-29 \%$ & $-3 \%$ \\
\hline
\end{tabular}

Fonte: Elaboração própria e CNJ (2017)

Nota: $\left({ }^{*}\right)$ As comparações apresentadas nas colunas (A-B) e (A-C) buscam apenas evidenciar que modelos diferentes implicam resultados distintos. Portanto, os dados nelas apresentados devem ser interpretados dentro desses limites.

Todos os demais tiveram eficiência acima de 70\%, à exceção de TRT 5 (Bahia, 66\%), TRT 13 (Paraíba, 63\%), TRT 14 (Rondônia e Acre, 66\%) e TRT 21 (Rio Grande do Norte, 67\%).

Os dados do IEP (coluna B), por sua vez, mostraram uma eficiência ainda mais elevada da Justiça do Trabalho brasileira, com 16 dos 24 tribunais na fronteira de eficiência (100\%): TRT 2 (São Paulo), TRT 3 (Minas Gerais), TRT 8 (Pará e Amapá), TRT 9 (Paraná), TRT 11 (Amazonas e Roraima), TRT 12 (Santa Catarina), TRT 14 (Rondônia e Acre), TRT 15 (Campinas), TRT 16 (Maranhão), TRT 17 (Espírito Santo), TRT 18 (Goiás), TRT 19 (Alagoas), TRT 21 (Rio Grande do Norte), TRT 22 (Piauí), TRT 23 (Mato Grosso) e TRT 24 (Mato Grosso do Sul).

Com exceção do TRT 13 (Paraíba, 63\%), todos os demais tiveram eficiência acima de $80 \%$.
O CNJ também utiliza o método DEA para comparar a eficiência dos Tribunais do mesmo ramo de atuação e elabora o Índice de Produtividade Comparada da Justiça (IPC-Jus), desde 2013. Assim como o IEP, realiza a análise considerando os portes desses tribunais.

Como se observa na coluna C da tabela 2, apenas quatro TRTs estão na fronteira de eficiência (100\%): TRT 8 (Pará e Amapá), TRT 11 (Amazonas e Roraima), TRT 15 (Campinas, SP) e TRT 3 (Minas Gerais). São 9 os que têm eficiência elevada (superior a 90\%): TRT 2 (São Paulo, 93\%), TRT 6 (Pernambuco, 91\%), TRT 7 (Ceará, 90\%), TRT 12 (Santa Catarina, 94\%), TRT 14 (Rondônia e Acre, 92\%), TRT 17 (Espírito Santo, 92\%), TRT 18 (Goiás, 99\%), TRT 21 (Rio Grande do Norte, 90\%) e TRT 22 (Piauí, 96\%), conforme o IPC-Jus, 
Os tribunais de menor eficiência (inferior a 80\%) foram: TRT 16 (Maranhão, 70\%), TRT 20 (Sergipe, 79\%) e TRT 24 (Mato Grosso do Sul, $74 \%)$.

Para o cálculo do IPC-Jus, o CNJ (2017) também assume retornos constantes de escala com orientação para o produto, mas usa outros inputs e outputs:

- $\quad$ Inputs $=($ processos que tramitam $(=$ processos baixados + processos pendentes)) + (despesa total - despesa com pessoal inativo - despesa com projetos de construção e obras) + (número de magistrados e de servidores efetivos, requisitados e comissionados sem vínculos - cedidos para outros órgãos).

- $\quad$ Outputs: processos baixados.

Uma análise desses resultados revela uma elevada eficiência da Justiça do Trabalho, qualquer que seja o modelo adotado, seja o desse artigo (com ou sem porte), seja o do CNJ. Em alguns casos, porém, algumas diferenças são grandes e merecem uma discussão.

Tais diferenças decorrem da escolha do modelo DEA que, como já explicado, é fator muito relevante e tem impactos diretos nos resultados obtidos na análise, fazendo-se necessário debruçar-se sobre essa questão, como faz a seção a seguir.

\section{Uma discussão sobre os modelos para 0 cálculo das eficiências dos TRTs}

Duas questões merecem atenção. A primeira decorre da observação de que quando se compara o TRT apenas com os demais do mesmo porte, como faz o IEP, há um expressivo aumento da eficiência: os dados do IEP (coluna B) são mais elevados que os do
IEG (coluna A). A segunda é relativa ao fato de que o modelo proposto por esse artigo é diferente do utilizado pelo CNJ em termos de inputs e outputs.

\subsection{O uso dos portes nos cálculos dos mo- delos DEA de análise da eficiência da justi- ça brasileira: um debate preliminar}

A primeira questão, relativa ao uso dos portes no modelo DEA, fica evidenciada quando se compara IEG com IEP, na coluna (A-B) da Tabela 2. Para alguns tribunais, notadamente os de pequeno porte, as diferenças em termos de eficiência são bastante elevadas. Esse é o caso de TRT 14 (Rondônia e Acre, -34\%), TRT 21 (Rio Grande do Norte, -33\%), TRT 24 (Mato Grosso do Sul, -29\%), TRT 23 (Mato Grosso, -25\%), TRT 19 (Alagoas, -25\%) e TRT 16 (Maranhão, -20\%). Entre os tribunais de médio porte, destacam-se o TRT 10 (Distrito Federal e Tocantins, -20\%), bem como TRT 5 (Bahia, -15\%) e TRT 9 (Paraná, -14\%).

Para outros, notadamente os de grande porte, não foi observada diferença, como foi o caso do TRT 2 (São Paulo), TRT 3 (Minas Gerais), TRT 4 (Rio Grande do Sul) e TRT 15 (Campinas, SP).

Ocorre que a classificação por portes adotada para o cálculo do IEP e pelo CNJ em seu modelo não parece apropriada para análise DEA, uma vez que esse método, cujo objetivo é identificar a DMU eficiente, ou seja, aquela com melhor relação output/input, precisa seguir algumas recomendações, não observadas nos cálculos com o uso dos portes dos TRTs.

Como mostrado na seção 4.1, a DEA calcula, em seu primeiro estágio, o desempenho da DMU na produção de outputs com os inputs que ela dispõe. Somente após identificados 
os tribunais mais eficientes e estabelecendo-se a fronteira de eficiência, hiperplano formado pelos TRTs com índices de 100\%, é que esses são utilizados como referencial para comparação com os demais. Portanto, a eficiência obtida pelo método DEA é relativa: é o resultado da comparação do que foi produzido, a partir dos recursos disponíveis, com o que poderia ter sido produzido com esses recursos, como explicam Mello et al. (2005).

Quanto menos comparações a serem feitas, isso é, menos DMUs envolvidas na análise, maior a possibilidade de muitas atingirem a fronteira de eficiência. Quando o número de unidades analisadas aumenta, os resultados mudam, podendo a DMU que foi eficiente deixar de ser com a inclusão das novas unidades, explica Guerreiro (2006). Assim, o tamanho do conjunto de TRTs a ser analisado influencia no número de unidades que serão consideradas eficientes.

Quando o IEP ou o CNJ empregam o método DEA com a divisão por portes, surgem 3 fronteiras de eficiência, reduzindo o número de comparações efetuadas. No caso dos tribunais de grande porte, são apenas cinco (TRT 1, TRT 2, TRT 3, TRT4 e TRT 15). Os de médio porte são dez (TRT 5, TRT 6, TRT 7, TRT 8, TRT 9, TRT 10, TRT 11, TRT 12, TRT 13 e TRT18) e os de pequeno porte, nove (TRT 14, TRT 16, TRT 17, TRT 19, TRT 20, TRT 21, TRT 22, TRT 23 e TRT 24). Ou seja, as diferenças entre os índices calculados são explicadas, em parte, porque menos comparações são efetuadas.

Uma questão relacionada à especificação desse modelo que considera a divisão por portes é quanto ao número de variáveis do modelo e a quantidade de DMUs em análise. A literatura especializada defende que o poder discriminatório da análise melhora quando se observa uma certa relação entre as variáveis e as unidades.

A recomendação de Fitzsimmons e Fitzsimmons (2005) é de que o mínimo aceitável de DMUs (n) deve ser igual ao dobro da soma dos inputs $(m)$ e outputs $(s): n=2(m+s)$.

Fochezatto (2010), reconhecido pelo próprio CNJ (CNJ, 2017) como referência da aplicação do método DEA na área forense, é ainda mais rigoroso e recomenda que esse número deve ser o triplo:

\begin{abstract}
Indica-se que o número de DMUs a serem analisadas deverá ser o triplo do número de variáveis do modelo. É importante manter o modelo o mais compacto possível, porque isso facilita a maximização do poder discriminatório do modelo DEA (FOCHEZATTO, 2010, p. 10)
\end{abstract}

Mello et al. (2005) destacam a importância dessa relação entre o número de DMUs em análise e o de variáveis, devendo-se evitar que isso resulte em uma avaliação benevolente, com muitas unidades sendo eficientes. Assim, lembram que González Araya (2003) sugere que o total de DMUs seja quatro a cinco vezes maior:

\begin{abstract}
Um modelo com grande número de variáveis pode acarretar outro problema, qual seja, uma avaliação extremamente benevolente, com várias DMUs 100\% eficientes. Existe uma recomendação empírica que o número de DMUs seja pelo menos o dobro ou o triplo do número de variáveis. Estudos mais recentes (GONZÁLEZ ARAYA, 2003) indicam que essa relação deve ser ainda maior ( 4 a 5 vezes), em especial quando, além do índice de eficiência, deseja-se analisar os benchmarks das unidades em avaliação (MELLO et al., 2005, p. 613).
\end{abstract}

Na mesma linha, Yeung e Azevedo (2012) destacam que, entre os cuidados necessários na aplicação do método DEA, deve-se respeitar a regra de o triplo de DMUs em relação à somatória de inputs e outputs, evitando que os resultados de eficiência derivados fiquem comprometidos. 
No modelo proposto nesse artigo, há 4 inputs e 2 outputs. Considerando-se a proposta de que o número de DMUs seja o dobro da soma das variáveis, seriam necessários pelo menos $12(=2 \times 6)$ TRTs para a aplicação do método DEA, o que não ocorre quando se observa que são 5 tribunais de grande porte, 10 de médio e 9 de pequeno porte.

Pelas mesmas razões, o poder discriminatório do modelo DEA do CNJ também fica prejudicada com o uso dos portes, posto que a soma de inputs e outputs é quatro. No caso da regra do dobro, seriam necessários pelo menos 8 (= $2 \times 4)$ TRTs em análise, o que não ocorre nos tribunais de grande porte, que são apenas 5. Adotando-se a regra do triplo, cada porte deveria ter pelo menos $12(=3 \times 4)$ TRTs, o que não ocorre.

Baseado nesses argumentos, optou-se por seguir a literatura de análise da eficiência dos tribunais judiciários pelos modelos DEA e não usar a classificação por portes nesse artigo." Assim, descartou-se o IEP em favor do Índice de Eficiência Geral (IEG) para expressar o grau de eficiência relativa de cada TRT.

\subsection{As especificações dos inputs e outputs dos modelos DEA para análise da eficiên- cia da justiça brasileira}

A segunda questão em foco nessa seção é relativa à diferença entre o modelo proposto por esse artigo e o utilizado pelo CNJ em termos de inputs e outputs.

Uma comparação entre os resultados das eficiências calculadas a partir de cada um pode ser observada na coluna $(\mathrm{A}-\mathrm{C})$ da Ta-

"Uma discussão mais aprofundada sobre os portes na análise da eficiência dos tribunais judiciários pode ser objetivo de um trabalho específico, no qual, por exemplo, poder-se-ia aplicar uma DEA em dois estágios, modelos que incorporam julgamentos de valor de especialistas, modelos de supereficiência ou de fronteira invertida. bela 2. Em 13 casos, o IPC-Jus foi mais elevado, sendo bastante acentuada para muitos tribunais de pequeno porte, como o TRT 14 (Rondônia e Acre, -26\%), TRT 21 (Rio Grande do Norte, -23\%), TRT 23 (Mato Grosso, -8\%) e TRT 19 (Alagoas, -8\%). No caso dos tribunais de médio porte, algumas diferenças também se destacam: TRT 13 (Paraíba, -19\%), TRT 5 (Bahia, -15\%), TRT 10 (Distrito Federal e Tocantins, -8\%), TRT 8 (Pará e Amapá, -7\%) e TRT 6 (Pernambuco, -5\%).

Além da questão do porte, não incluída no cálculo do IEG, o output é formado por sentenças e decisões de segundo graus, entendendo-se que esses produtos mais se aproximam de procedimentos relativos à prestação dos serviços públicos à sociedade, bem como estão melhor adequados aos inputs escolhidos.

No caso dos inputs, as diferenças com relação ao modelo do CNJ estão na exclusão da despesa e dos processos que tramitam, bem como na inclusão da variável tempo. Faz-se necessário lembrar que as hipóteses de retornos constantes de escala e de orientação para o output para o uso do método DEA requerem selecionar recursos que os tribunais possam melhorar a produtividade. Por serem os recursos financeiros da Justiça do Trabalho definidos por outros poderes (Legislativo, Executivo) e/ou órgãos judiciais de hierarquia superior, acredita-se que a análise melhora quando esses não são considerados do modelo.

Optou-se, então, pela inclusão da variável tempo como input pelo fato de que a morosidade é um dos principais problemas apontados pela sociedade como causa da insatisfação com o Poder Judiciário, juntamente com o custo alto e a dificuldade de acesso. Segundo o índice de confiança na 
justiça (ICJ), divulgado no Relatório ICJBrasil, a confiabilidade dos brasileiros no Poder Judiciário está em baixa, alcançando somente $24 \%$ em 2017. O mesmo documento atesta que $81 \%$ dos entrevistados reclama da demora de o Judiciário na resolução dos casos (resolve lenta ou muito lentamente) e um elevado percentual (73\%) o considera nada ou pouco competente para solucioná -Ios (FGV Direito SP, 2017).

Porém, até o Justiça em Números 2016, eram poucas as estatísticas oficiais disponíveis sobre o tempo do processo, ficando restritas à taxa de congestionamento. Ocorre que esse dado não diz muito sobre a entrega da jurisdição no Brasil, como reconhece o próprio texto oficial. Indica apenas o percentual de processos iniciados em anos anteriores e que ainda não tiveram soluções.

Uma das explicações para essa falta de dados é que o tempo do processo é de difícil apuração, posto que são muitas as combinações de situações de fato e de direito que uma ação judicial pode ter no Brasil (CNJ, 2016). Por ser uma média de dados muito dispersos, reunir as informações em apenas um número é uma tarefa complexa. E mais, a díspar realidade das diversas cortes brasileiras, nem todas com condições adequadas de prestar corretamente a informação, reflete-se na baixa qualidade de alguns registros e da sistematização de informações processuais.

Por fim, as várias combinações do fluxo de litigiosidade do processo, dependendo do ramo de justiça e de outras características, como os recursos disponíveis, muito afetam seu tempo de duração. Torna-se, pois, difícil estimar um tempo adequado para a duração média dos mesmos, como evidenciado na discussão acerca do princípio da razoável duração do processo (Emenda Constitucional n45/2004).

Já no caso do output escolhido pelo $\mathrm{CNJ}$, os processos baixados, a crítica trazida por esse artigo é pelo fato de que ele não traduz os resultados quanto ao que se espera da justiça em termos de solução do litígio de quem buscou a tutela de seu direito violado.

De acordo com o glossário da Resolução CNJ n. 76/2009, consideram-se baixados os processos nas seguintes situações:

- Remetidos para outros órgãos judiciais competentes, desde que vinculados a tribunais diferentes;

- Remetidos para as instâncias superiores ou inferiores;

- Arquivados definitivamente; e

- Em que houve decisões que transitaram em julgado e iniciou-se a liquidação, cumprimento ou execução.

Ou seja, os processos baixados incluem uma série de situações que não refletem processos efetivamente solucionados, quer dizer, com resolução de mérito. Ao incluírem os arquivamentos de processos por desistência formal ou pela ausência da parte na audiência inaugural, por exemplo, isso não diminui a morosidade, tampouco garante o que o jurisdicionado buscou ao procurar a garantia do seu direito violado.

Versam as Emendas Constitucionais $n^{\circ}$ 19/1998 (o princípio da eficiência) e $n^{\circ}$ 45/2004 (princípio da razoável duração do processo), que a atuação do Poder Público e do Poder Judiciário, em particular, devem pautar-se em critérios de celeridade, eficiência e efetividade a fim de elevar a confiança da coletividade. Para isso, não é suficiente a 
elevação à condição de constitucional desses preceitos, mas sim que busquem atender os direitos dos cidadãos, quanto a uma tutela adequada, eficaz e célere, o que não tem sido a realidade nacional.

É dever do CNJ produzir indicadores coerentes com esse objetivo, o que significa, entre outros aspectos, aperfeiçoar os outputs dos modelos, pois a entrega da prestação jurisdicional não pode ser resumida ao número de processos baixados.

Nesse sentido, os outputs escolhidos no modelo aqui proposto para o cálculo do IEC foram as sentenças de primeiro grau e as decisões de segundo grau, pois apesar de não expressarem com precisão o alcance dos objetivos constitucionais em discussão, foram, dentre os disponibilizados no Sistema de Estatísticas do Poder Judiciário, os que mais se aproximaram de uma variável que denote o encerramento da lide com a adequada prestação jurisdicional.

Contudo, reconhece-se a limitação do uso desse output, pois faz-se necessário levar em consideração a qualidade das sentenças e efetiva solução dos litígios, o que indica a necessidade de maiores estudos para a inclusão de variáveis ligadas a processos com resolução de mérito e o consequente atingimento dos objetivos constitucionais.

\section{Considerações finais}

O artigo analisou os Tribunais Regionais do Trabalho no Brasil sob a ótica da eficiência, uma vez que esse é um dos princípios definidos constitucionalmente e importante para dar efetividade ao papel a ser por ela desempenhado. Assim, pretendeu-se destacar que esse é um critério importante para a avaliação do funcionamento da Justiça do Trabalho, bem como para a elaboração de possíveis críticas a ela, o que não ocorre com alguns argumentos levantados a favor de sua extinção, os quais parecem não ter fundamentação na CF/88.

Buscou-se mostrar a importância desse ramo da justiça para a estabilidade das relações sociais, para a observância das garantias mínimas para os trabalhadores, para assegurar o direito fundamental ao trabalho, bem como para a criação de um ambiente de trabalho mais favorável.

A análise aqui apresentada confirmou a elevada eficiência da Justiça do Trabalho, já atestada pelo CNJ no cálculo do IPC-Jus. Os dados mostram que seis tribunais estão na fronteira de eficiência (100\%) e todos os demais com índices acima de 70\%, à exceção de TRT 5 (Bahia, 66\%), TRT 13 (Paraíba, 63\%), TRT 14 (Rondônia e Acre, 66\%) e TRT 21 (Rio Grande do Norte, 67\%).

Os resultados acima referem-se ao IEG, índice calculado com base no modelo DEA desenvolvido por esse estudo, que fez uma crítica ao uso dos portes dos tribunais para avaliar sua eficiência, bem como propôs diferentes inputs e outputs que os utilizados pelo CNJ.

Mostrou-se que a classificação dos tribunais por portes, como faz o Conselho, não parece apropriada para análise DEA, uma vez que o método precisa seguir algumas recomendações da literatura especializada, relativas ao número de variáveis do modelo e à quantidade de DMUs. O poder discriminatório do modelo do CNJ fica prejudicado com o uso dos portes, posto que a soma de inputs e outputs não segue tais recomendações.

O artigo também discutiu os inputs e outputs os utilizados pelo Conselho. Como 
input, defendeu-se a inclusão da variável tempo no cálculo da eficiência dos tribunais, dado que a morosidade é um dos principais fatores que ensejam a insatisfação dos brasileiros com o Poder Judiciário.

Para o caso do output, os processos baixados, a crítica destacou o fato de que os mesmos não traduzem os resultados de quem espera a solução do litígio, a tutela de um direito violado, buscando a justiça.

Como se viu, os processos baixados referem-se a uma série de situações que não podem ser compreendidas como processos efetivamente solucionados, os com resolução de mérito. Como exemplo, mostrou-se que esse output inclui arquivamentos de processos por desistência formal ou pela ausência da parte na audiência inaugural, o que certamente nem diminui a morosidade, nem garante a tutela do direito violado de quem propôs uma ação judicial.

Reconhece-se, todavia, a limitação do uso do output usado por esse artigo como proposta alternativa, posto que sentenças e decisões certamente deixam a desejar enquanto "produtos" dos tribunais. Reteira-se, nesse sentido, a importância de incluir indicadores de qualidade das sentenças e da efetiva solução dos litígios, evidenciando-se a importância de que novos dados sejam disponibilizados pelo $\mathrm{CNJ}$, viabilizando estudos que considerem variáveis ligadas a processos com resolução de mérito e o consequente atingimento dos objetivos constitucionais do judiciário. Com os dados disponíveis até o momento, e tendo como base os modelos testados, não se pode acusar os TRTs de ineficiência, não havendo sustentação para os questionamentos apresentados por aqueles que defendem sua extinção.

Destaca-se, por fim, a importância de novas pesquisas propondo outros modelos, como os de análises em dois estágios, os que incorporam julgamentos de valor de especialistas, os modelos de supereficiência e de fronteira invertida, aprofundando questões sobre o uso dos portes no cálculo do IPC-Jus ou sobre os inputs e outputs a serem considerados em estudos sobre a eficiência dos TRTs.

\section{Referências}

Alexandrino, M.; Barreto, G., \& Paulo, V. (2006). Direito do Trabalho ( $9^{a}$ ed). Rio de Janeiro: Impetus.

Banker, R., Charnes, A., \& Cooper, W. (1984). Some Models for Estimating Technical and Scale Inneficiencies in Data Envelopment Analysis. Management Science, 30 (9), 1078-1092.

Calhao, A. E. P. (2007). O Princípio da Eficiência na Administração da Justiça. São Paulo: RCS.

(2010). Justiça célere e eficiente: uma questão de governança judicial. São Paulo: LTr.

Camargo, F., Guimarães, K. (2013). O princípio da eficiência na gestão pública. Revista CEPPG-CESUCCentro de Ensino Superior de Catalão, Ano XVI (28), $133-145$

Cassar, V. (2017). Direito do trabalho: de acordo com a reforma trabalhista. Lei 13.467/2017. 14ª ed. São Paulo: Ed Método.

Castelar Pinheiro, A. (2009). Impacto sobre o crescimento: uma análise conceitual. In: Castelar Pinheiro, A (org). Judiciário e economia no Brasil. Rio de janeiro: Centro Edelstein de Pesquisas Sociais, 1-40.

Charnes, A., Cooper, W., \& Rhodes, E. R. (1978). Measuring the Efficiency of Decision-Making Units. European Journal of Operational Research, 2 (6), 429-444. CONSELHO NACIONAL DE JUSTIÇA - CNJ. (2018). Banco de dados do Sistema de Estatísticas do Poder Judiciário. Recuperado em 7 jan., 2018, de http://www. cnj.jus.br/programas-e-acoes/pj-justica-em-numeros/2013-01-04-19-13-21.

Justiça em Números $(2013,2017)$. Recuperado em 9 janeiro, 2018, de: http://www.cnj.jus.br/ programas-e-acoes/pj-justica-em-numeros.

Da Ros, L. (2015). O custo da Justiça no Brasil: uma análise comparativa exploratória. Observatório de elites políticas e sociais do Brasil, 2 (9). Recuperado em 10 maio, 2018, de: http://observatory-elites.org/wp- 
content/uploads/2012/06/newsletter-Observatorio-v.2-n.-9.pdf

Delgado, G. N. (2013). A CLT aos 70 anos: rumo a um Direito do Trabalho constitucionalizado. Revista TST, 79 (2), 1-38.

Faria, J. E. A crise do judiciário no Brasil. (2005). In J. B. Lima Junior (org). Independência dos juízes: aspectos relevantes, casos e recomendações (pp. 23-52). Recife: Gajop; Bagaço.

Fitzsimmons, J., \& Fitzsimmons, M. (2005). Administração de serviços: operações, estratégia e tecnologia da informação (4a ed). Porto Alegre: Bookman.

Fochezatto, A. (2010). Análise da Eficiência Relativa dos Tribunais de Justiça Estadual Brasileira Utilizando o método DEA. Recuperado em 7 outubro, 2017, de: http://www.aecr.org/ web/congresos/2010/htdocs/ pdf/p50.pdf.

Fundação Getúlio Vargas - FGV / Direito SP (2017). Relatório ICJBrasil. Recuperado em 19 fevereiro, 2018, de: http://bibliotecadigital.fgv.br/dspace/bitstream/handle/10438/19034/Relatorio-ICJBrasil_1_sem_2017.pdf?sequence=1\&isAllowed=y

Gico Júnior, I. T. (2014). A tragédia do Judiciário. Revista de Direito Administrativo, 267, 163-198.

Gomes, A. M. C. (2006). Retrato falado: a Justiça do Trabalho na visão de seus magistrados. Revista Estudos Históricos, 1 (37), 55-80.

Gomes, E. G., Mangabeira, J. A. C., \& Mello, J. C. C. B. S. (2005). Análise de envoltória de dados para avaliação de eficiência e caracterização de tipologias em agricultura: um estudo de caso. Revista de Economia e Sociologia Rural, 43 (4), 607-631.

Gonçalves, D. M., \& Souza, F. F. (2014). As limitações da Emenda Constitucional n. ${ }^{\circ}$ 19/98 na implementação do modelo gerencial de administração pública no Brasil. Florianópolis: CONPEDI, 1, 73-87.

González Araya, M. (2003). Projeções não radiais em regiões fortemente eficientes da fronteira DEA - algoritmos e aplicações. Tese de Doutorado em Engenharia de Produção, Universidade Federal do Rio de Janeiro, Rio de Janeiro, RJ, Brasil.

Guerreiro, A. S. (2006). Análise da Eficiência de Empresas de Comércio Eletrônico usando Técnicas da Análise Envoltória de Dados. Dissertação de mestrado do Programa de Pós-Graduação em Engenharia de Produção do Departamento de Engenharia Industrial, Pontifícia Universidade Católica, Rio de Janeiro, RJ, Brasil.

Kittelsen, S.A.C., \& Førsund, F. R. (1992). Efficiency analysis of Norwegian district courts, The Journal of Productivity Analysis, 3, 277-306.

Leal, R. G.. (2010). Impactos econômicos e sociais das decisões judiciais: aspectos introdutórios. Brasília: ENFAM.

Lewin, A., Morey, R., \& Cook, T. (1982). Evaluating the administrative efficiency of courts. Omega 10, 401-411. Marco, C. M. de, \& Medeiros, J. F. de. (2016). O princípio da eficiência da administração da justiça como justificativa para implantação de uma jurisprudência precedentalista no Brasil: a disciplina judiciária marcada por influência neoliberal. Revista Jurídica, 3 (40), 358-376.

Martins, S. P. (2017). Manual de Direito do Trabalho (10ª ed). São Paulo: Saraiva.

Mello, J. C., Meza, L. A., Gomes, E., \& Biondi Neto, L. (2005). Curso de análise de envoltória de dados. Anais do Simpósio Brasileiro de Pesquisa Operacional, Gramado, RS, Brasil, 37, 2521-2547.

Moreira, H. D. R. F. (2007). Poder Judiciário no Brasil Crise de Eficiência. Curitiba: Editora Juruá.

Morel, R. L. M.; \& Pessanha, E. (2007). A justiça do trabalho. Tempo Social, revista de sociologia da USP, 19 (2), 87-109.

Nogueira, J. M. M., Oliveira, K. M. M., \& Vasconcelos, A. P. (2012). Estudo exploratório da eficiência dos Tribunais de Justiça estaduais brasileiros usando a Análise Envoltória de Dados (DEA). Revista de Administração Pública, 46 (5), 317-1340.

Peluso, C. (2010). Consolidação da democracia e reforma do judiciário no Brasil. Apresentação no seminário Brazil Judicial Reform, promovido pelo Banco Mundial, em Washington. Recuperado em 18 novembro, 2016, de: http://www.stf.jus.br/repositorio/cms/portalStfInternacional/ portalStfDestaque_pt_br/anexo/discursoWashington2.pdf

Sadek, M. T. (2004). Judiciário: mudanças e reformas. Estudos Avançados, 18 (51), 79-101.

Santos Neto, M., Souza; L. A. C, \& Bortolon, P. M. (2016). Análise da Eficiência dos Tribunais Estaduais do Brasil: Aplicação da Técnica de Análise Envoltória de Dados e Regressão Logística. In: Congresso ANPCONT, 10, Ribeirão Preto, SP. Recuperado em 03 julho, 2017, de: http://congressos.anpcont.org.br/x/anais/files/2016-05/ cpt234.pdf.

Souza, B. L. A. (2015). Mensurando a eficiência do judiciário brasileiro: uma abordagem DEA em dois estágios. Dissertação de mestrado do Programa de PósGraduação em Economia, Brasília, DF, Brasil. 
Uribe, G., \& Alegretti, L. (2018, 17 janeiro). TST rebate Jefferson e diz que extinção da Justiça do Trabalho é retrocesso. Folha de São Paulo, Caderno Poder, São Paulo, SP. Recuperado em 02 abril, 2018, de: http:// www1.folha.uol.com.br/poder/2018/01/1951150-tst-rebate-jefferson-e-diz-que-extincao-de-justica-do-trabalho-e-retrocesso.shtml

Uribe, G., \& Carvalho, D. (2018, 17 janeiro). Justiça trabalhista é 'babá cara', diz Roberto Jefferson. Folha de São Paulo, Caderno Poder, São Paulo, SP. Recuperado em 02 abril, 2018, de: http://www1.folha.uol.com.br/poder/2018/01/1951046-justica-trabalhista-e-baba-caradiz-roberto-jefferson.shtml

Yeung, L. L., \& Azevedo, P. F. de. (2012). Além dos "achismos" e das evidências anedóticas: medindo a eficiência dos tribunais brasileiros. Economia Aplicada, 16 (4), 643-663.

\& Garcia, G. A. (2014). Análise de Eficiência da Justiça Eleitoral no Brasil. Cadernos Adenauer, XV (1), 211-228. Justiça Eleitoral Rio de Janeiro e Fundação Konrad Adenauer.

Zaidan, C. A. L (2011). Análise do Poder Judiciário brasileiro: quantificando sua eficiência através da Análise Envoltória de Dados - DEA. Recife: O Autor.

(2012). Conselho Nacional de Justiça e a eficiência no Poder Judiciário do Brasil. Recife: O Autor.

Data de submissão: 23/05/2018

Data de aceite: 31/03/2019 